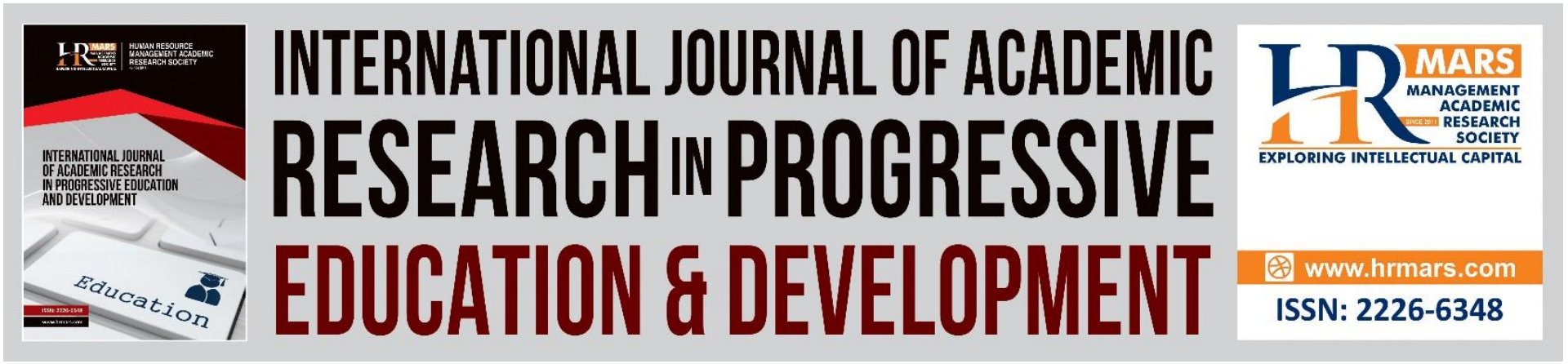

\title{
Delivery of Sexuality Education to Students with Intellectual Disabilities in Secondary Schools: Educators' Perspective
}

Siti Aisyah Maszarry, Ardzulyna Anal, Rohaizat Ibrahim

To Link this Article: http://dx.doi.org/10.6007/IJARPED/v10-i4/11844

DOI:10.6007/IJARPED/v10-i4/11844

Received: 12 September 2021, Revised: 16 October 2021, Accepted: 30 October 2021

Published Online: 19 November 2021

In-Text Citation: (Maszarry et al., 2021)

To Cite this Article: Maszarry, S. A., Anal, A., \& Ibrahim, R. (2021). Delivery of Sexuality Education to Students with Intellectual Disabilities in Secondary Schools: Educators' Perspective. International Journal of Academic Research in Progressive Education and Development, 10(4), 84-93.

Copyright: (C) 2021 The Author(s)

Published by Human Resource Management Academic Research Society (www.hrmars.com)

This article is published under the Creative Commons Attribution (CC BY 4.0) license. Anyone may reproduce, distribute, translate and create derivative works of this article (for both commercial and non-commercial purposes), subject to full attribution to the original publication and authors. The full terms of this license may be seen

at: http://creativecommons.org/licences/by/4.0/legalcode

Vol. 10(4) 2021, Pg. 84 - 93

http://hrmars.com/index.php/pages/detail/IJARPED

JOURNAL HOMEPAGE

Full Terms \& Conditions of access and use can be found at http://hrmars.com/index.php/pages/detail/publication-ethics 


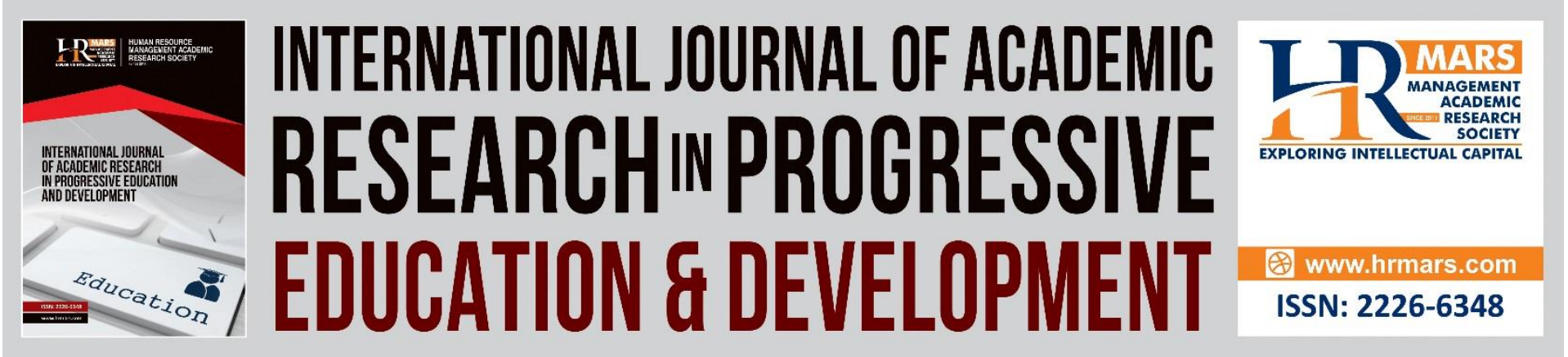

\title{
Delivery of Sexuality Education to Students with Intellectual Disabilities in Secondary Schools: Educators' Perspective
}

\author{
Siti Aisyah Maszarry, Ardzulyna Anal, Rohaizat Ibrahim \\ Universiti Pendidikan Sultan Idris, Tanjung Malim, Malaysia
}

\begin{abstract}
The issue of sexuality education is not a new thing in today's education. However, the implementation of sexuality education or talking about sexuality is a controversial issue and considered sensitive by some. This is because the term 'sex' carries different connotations to some people, and this is still considered a stigma by our society. Malaysia society is generally negatively prejudiced on the issue of the implementation of sexuality education for students with learning difficulties. The purpose of this study was to identify teachers' perceptions of the challenges of sexuality education delivery. This study uses a qualitative approach, and three study participants were selected in a school in the district of Kuala Selangor. The instrument used in this study was a semi -structured interview. Data obtained through interviews will be transcribed. The results of this study found that teachers argued that the challenges of sexuality education delivery consisted of no specific guidelines, less skilled teachers, students with various disabilities and parental and community acceptance. Implications from this study, it was found that teachers' perception of sexuality education is positive, but the upper party needs to make a specific guideline in addition to providing training to teachers.
\end{abstract}

Keywords: Sexuality Education, Teacher Perspective, Students with Intellectual Disabilities, Special Education, Secondary Schools.

\section{Introduction}

People with disabilities have the right to health information and services and that is to include sexual and reproductive rights, according to the UN Convention on the Rights of Persons with Disabilities (Nelson, 2020). In relation with that, there has been an increasing international awareness and commitment to improve sexual health and reproduction for students with intellectual disabilities (ID). Nevertheless, students with ID continues to face negative social stigma and has limited access to education and sexual health information. Many do not accept the fact that sexuality education can improve the needs and development of students with ID (Holland-Hall \& Quint, 2017). The public's faulty impression of students with ID, believing that they are like a child and have no sexual desire, causes them to think in such a way that sexuality education is not a necessity (Frawley and Wilson, 2016). 
Students with ID in Malaysia consist of various categories of disability, such as retarded sense, down syndrome, autistic, hyperactive and hypoactive problems. Although students with these different disability categories face problems related to cognitive and behavioral developments, their interests in sentimental relations and sexual desires should not be denied (Michielsen \& Brockschmidt, 2021). In addition, they have the same physical development as those students without disabilities (Gonzálvez et al., 2018). Hence, it is believed that they, too, are entitled to receive sexuality education, particularly in terms of self-cultivation capabilities as well as addressing sexual behavioral problems.

Learning that students with ID have sexual needs similar to their peers without disabilities, it is important to note that their needs may at times exceed their peers' (those without disabilities) needs and this could be due to certain specific problems, such as their limited ability to address sexual behaviour (Holland-Hall \& Quint 2017). To address such issue, research has shown that sexuality education for students with ID may be one possible way out (McCann et al., 2019). Nevertheless, incomplete and inadequate sexuality education has been identified to be a major factor that prevents the development and implementation of sexuality education for students with ID (Carvalho \& Silva, 2018). The need of sexuality education amongst special needs students is no longer a new issue hence warranting a rather serious look and deeper studies.

\section{Background}

Negative prejudice on sexuality education emerges as many people assume that sexuality education means education related to sexual treatment. According to Eyres et al (2016), sexuality education often prioritizes male and female sexual anatomy as well as sexual intercourse. In fact, comprehensive sexuality education reaches the physical aspects of sexual intercourse and encompasses many topics. Some of these topics include the problem of selfawareness and body image, interpersonal social skills, personal care and hygiene, developing relationships, risk prevention, and sexual expression, as well as legal aspects of sexual activity (Wu \& Zeng, 2020).

A society that is not open-minded about the importance of sexuality education has also contributed to the weakness of the implementation of sexuality education in Malaysia (Khalaf et al., 2014). The religious and cultural diversity of Malaysian society also affects the effectiveness of sexuality education. Certain religions, values and culture view certain parts of sexuality education as sensitive issues, hence preventing the delivery of such education in this country. Nelson and Pettersson (2019), stated that Swedish teachers felt this issue of sexuality education was sensitive and in turn prevented them from talking comfortably. They reported the possibility of a clash between students' cultural and religious beliefs, requiring a balance in teachers' ideas about right and wrong.

According to Gonzálvez et al (2018), scholarly studies have reported several negative effects of the absence of sexuality education for students with ID. Among others, students' engagement in inappropriate sexual behavior, low self-esteem, unsafe sexual practices and involvement in sexual abuse. Therefore, having a good sexuality education program will contribute to improved quality of life among these students with ID (Grove et al., 2018). Having discussed that, the need for sexuality education among students with special needs requires serious attention and warrants proper studies be conducted in order to scrutinise the issue. 


\section{Sexuality Education for Students with Intellectual Disabilities}

Sexuality education in school is known as Family Health Education (FHE). It aims to promote a healthy and responsible lifestyle (Rahman, 2020). These elements of FHE have been taught in secondary schools through subjects like Physical and Health Education; Science; Biology; and Moral and Islamic Education since the implementation of the Integrated Secondary School Curriculum in 1989. According to Ihwani et al (2015) who reviewed the recent literature on sexuality education in schools and the role played by social factors in adolescent sexual behavior, sexuality education taught in schools is yet to be considered as effective. Aside from the fact that there has been no specific subject on it, teachers have been found to be reluctant to teach sex related topics which could be due to lack of preparation and proper trainings (Wu \& Zeng, 2020).

According to Rooks-Ellis et al (2020), when students with disabilities enter puberty, they experience the same desires and physiological responses as other adolescents. Therefore, sexuality education should be delivered so that they can understand the changes in their physical, emotional and sexual development. In relation with that, Swango-Wilson (2011) stated that sexuality education has been identified as a mechanism to prevent the occurrence of sexual abuse against this group. Students with ID often engage in inappropriate sexual behaviours and cause discomfort to the surrounding community such as being naked in public, masturbating in public, improper handling of used menstrual products, and not knowing the boundaries that can contribute to the negative stigma of society (Holland-Hall \& Quint, 2017).

However, the lack of knowledge, skills, and confidence of teachers in delivering sexuality education to students with ID are among the reasons contributing to those improper behaviours shown by the students. These students are unable to identify the boundaries of wrong or right sexual behavior. According to Ballan and Freyer (2017), the need for sexuality education as a self-protector is an important aspect to be taken into consideration. To illustrate, female students with ID are among the easy targets of sex trafficking as they have limited understanding of sexual or romantic relationships and their sexual behavior (Lane et al., 2019). Therefore, teachers play an important role in conveying sexuality education information correctly and effectively.

Furthermore, teachers need to have knowledge of sexuality education and be skilled in delivering sexuality education effectively to students. Although there are elements of sexuality education in the existing curriculum in Malaysia, there is no clear guideline for teachers on how to convey the information (Ang \& Lee, 2013). So, this causes teachers to have limited knowledge and skills in delivering sexuality education to students with learning difficulties. In addition, the diversity of students with ID categories is also a barrier to delivering a quality sexuality education. There are different levels of intellectual ability and sexual experience in one class. This diversity in turn becomes a major challenge for teachers to balance appropriate teaching content and methods (Nelson \& Pettersson, 2019).

Parental intervention in sexuality education may increase their knowledge and this, would hence change their beliefs, attitudes and behaviours about the need to educate their children about sexuality (Rooks-Ellis et al., 2020). Similarly, sexuality education interventions can encourage parents to communicate with their children regarding this topic. However, parents and children with disabilities show no interest in the development of this sexuality education. Therefore, high-quality teaching guidelines and resources need to be planned for educators and families (Treacy et al., 2018). Efforts to compile principles and guidelines for 
sexuality education for all adolescents especially students with ID in Malaysia are highly warranted.

\section{Purpose of Study}

Based on the problem statement, this study was conducted to explore the perceptions of special education teachers on the challenges of delivering sexuality education for students with intellectual disabilities in secondary schools in Malaysia.

\section{Research Method}

This study used a qualitative approach to meet the research objective. Aiming at identifying teachers' perceptions of the challenges in delivering sexuality education to students with ID, this study involved only the qualitative views of teachers on sexuality education. Hence, a case study was employed.

As to yield detailed and complete results, semi-structured face to face interviews were conducted with three teachers teaching special education. These select teachers were believed to be the main source of the required data. According to Saunders et al. (2019), faceto-face interviews allow for better rapport development between the researcher and each study participant, other than reducing any participants' concerns when sharing data with the researcher. Additionally, face-to-face interviews can lead to open and honest discussions.

Certain themes and related questions have been predetermined and this development of the interview protocol was validated by three experts prior to the interview sessions. With such face and content validation, the opinions of all experts were taken into account in determining the selection of questions of the interview. Guided by the validated interview protocol, followed by the process of obtaining the participants' consent, the data were collected and recorded. The recordings of the interview were then transcribed to be used as the main evidence in this study. Upon completion of the transcript making process, text validation by study participants was carried out. The whole interview procedures, conducted with participants, gave the researcher clear understanding of the researched topic. The validated transcribed data were then analysed using the thematic analysis.

\section{Results}

Generally aimed to explore the delivery of sexuality education in a secondary school, data were obtained through in depth semi structured interviews with three selected special education teachers. The researcher reports, explains and discusses the results based on the following four themes:

a) Lack of Guideline

Two study participants argued that no guidelines were specifically created for the teaching of sexuality education to students with ID. Because of this, teachers have difficulty finding appropriate teaching materials and resources to teach the students.

R2: "there is no clear guideline to teachers on how to convey the information."

R3: "Because there is no guideline for sexuality education at the curriculum level."

Following the issue of no guideline prepared for teachers, participants spoke about the need of preparing such guidelines. Considering the diversity of students who come from various religions, races and ethnicities in the country, participants also shared that the production of good guidelines should take into account the shared values. This is to ensure 
that the guidelines and the practice following them do not provoke any controversial issues among the students, the teachers and the community.

R3: "The important reason is to create guidelines like I said before, it is necessary to create guidelines so that the content is in accordance with the application of our country's values and in accordance with religious guidelines. As we know, our country is multi-racial, so we need to follow our respective religious norms."

\section{b) Unskilled Teacher}

Results also identified that unskilled teachers made sexuality education unworkable. In the view of the study participants, they had never been given any trainings on the teaching of sexuality education and this, in turn, caused them not to know what should be taught to the students.

R2: "...lack of training and lack of appropriate teaching material resources.. teachers also need to be exposed to effective methods of conveying sexual information. So it's like preparing a course for the teachers before teaching the students."

As explained by R3, "Because we have to understand the topic to teach the subject. So, the ministry needs to create a guideline as well as training on how to deliver this sexuality education, how to teach what is necessary and suitable for teachers to teach at the school level." Therefore, if teachers themselves do not have specific and clear trainings on the teaching, it is a big challenge for them to convey the lessons to the students with ID.

c) Diversity of Cognition among Students with ID

Through the results of the interviews, the study participants argued that they face difficulties in teaching sexuality education as there are various cognitive levels of students in one class. Students with low intellectual level normally have difficulty understanding the lessons and this require extra efforts from the teachers to balance the teaching within a classroom containing students with different cognitive abilities.

R1: "It is a big challenge for special education teachers to teach because we know special education students in terms of cognitive problems. So the acceptance of the student is different for each student."

R2: "The challenge for students here is when students who engage in sexual behavior do not know what they are doing due to their cognitive inability to think or understand aspects of sexual development."

R3: "Because in special education, in one class there are many levels of students... There is the lowest level of no function, the medium level, the highest".

Thus, by considering the variety of disabilities of these students, a clear guideline should be provided to teachers on appropriate teaching strategies to face such challenges. Module development studies specific to students from this category can also be conducted to facilitate teachers to plan appropriate lessons according to the categories of students' disabilities.

d) Parental and Society Acceptance

Results also indicate low level of acceptance towards sexuality education among the community, especially parents. Participants agreed that parents are still embarrassed when 
talking about sexuality education. This could be due to certain religious, cultural and community factors which do not explicitly allow open discussion on such topics.

R1: "Actually, sexuality education may be a bit difficult if we want to be created in our society. Especially, our society is often closed in this matter because we parent at home do not even explain the right things..."

R2: "There is no need for us to hide anything, kids need to be exposed. If parents had explained at home and they are used to hearing so they will easily accept what the teacher teaches at school."

Through the results of the interviews, the participants agreed that the implementation of sexuality education should begin at home so that students can better understand the issue. This would lead to better self-protection as well. Parents need to be open-minded to explain and tell the truth so that students do not misunderstand. Through this home education it also helps students not to engage in sexual behaviour in public.

\section{Discussion}

Results show that teachers are willing to teach sexuality education to students with ID. However, there is no clear guideline related to this teaching. In fact, teaching resources are difficult to find because they are not compatible with students with ID. According to Shariza (2017), a Chirawu study in 2014 found that special education teachers, of students with ID, responded positively towards comprehensive sexuality education. Nevertheless, about fiftyfive percent of special education teachers believed that the lack of sexuality education teaching materials for students with ID is the reason why sexuality education is difficult to conduct (Wang \& Nur, 2019). Therefore, teaching resources on sexuality education are needed to facilitate teachers to deliver the education well for the students implicated with ID. Hence, the production of good guidelines is warranted, considering the religion and culture aspects of the community living in Malaysia so as to keep the teaching safe and harmonious.

Special education teachers also face challenges in delivering sexuality education to students with ID as they are less skilled in conveying information related to sexuality education. This could be due to the limited trainings they received. A study by $\mathrm{Wu} \&$ Zeng (2020) found that seventy percent of special education teachers in China agreed that sexuality education is very important for students with ID yet half of them have no practical experience. In addition, Ujang's (2016) study in Malaysia found that there is no specific sexuality education training for special needs teachers. Teachers therefore need specialized training in delivering this sexuality education teaching because teachers need to know clearly about the content and skills that need to be used.

Besides, teachers found it challenging to deliver sexuality education to students with various cognitive disabilities. Some students find it difficult to understand the teaching. In fact, different levels of intellectual ability and sexual experience of students make teaching difficult. Teachers at times find it challenging to understand students' abilities and students' attitude change depending on the subject or situation they face (Nelson, 2020). Students with ID were identified to have difficulty in concentrating, reading, reasoning, besides having weak social skills. The cognitive level of students is limited, yet their sexual development is somehow in line with their chronological age (Michielsen \& Brockschmidt, 2021). Problems occur when students are unable to understand the sexual development that is happening to 
them. This cognitive limitation may create more problems as students with ID are sometimes unable to distinguish between right and wrong behaviors.

Another challenge in delivering sexuality education is in terms of the acceptance of parents and society. There are studies that show parents with lesser acceptance level to sexuality education training has caused them to be less confident to pass it on to children. According to Wu and Zeng (2020), the attitude of parents who are not open results in sexuality education not being taught at home. This is because parents still feel embarrassed when talking about sexuality education, and this could be due to certain religious, cultural and community stigma that sexuality education becomes a taboo in the society. Hence, parents need to be exposed to their roles to provide early sex education for children at home, especially those with ID. Parents, too, should be aware that children have the right to get the right information about sexuality (Yoisangadji, 2016).

\section{Conclusion}

The results of this study have resulted in several practical implications. Among others, the study suggests that relevant parties like the Ministry of Education Malaysia, special education teachers and school administrators take proper actions in ensuring the successful implementation of sexuality education. This includes the production of a proper guideline on teaching sexuality education to students with ID. Not only that, providing trainings to teachers is also a necessity as teachers need to learn the best practices in dealing with challenges in delivering the sexuality education to students with diverse ID backgrounds. As everybody is well mentioned, schools are the main source of information and learning, therefore the education provided needs to be of quality in order to support students in their transition from childhood to adulthood (Nelson, 2020). Other than that, parents, too, must be exposed to the importance of sexuality education for children with ID. When parents have such awareness, proper training could also be provided to those parents as to help them deliver the education needed by their children implicated with ID.

In relation with that, researchers recommend that studies on parental involvement in sexuality education be conducted so that parental knowledge and skills about sexuality education may be empirically identified. This is because, parental responsibilities do not only include or are limited to material needs, but also cover all aspects of their lives, including aspects of sexual education (Setianti et al., 2017). All in all, it is hoped that this paper provide insight related to the challenges teachers face in the implementation of sexuality education in Malaysia, hence several practical implications and future research recommendations to be considered by related stakeholders.

\section{Acknowledgement}

First and foremost, "Syukur Alhamdulillah" to Allah SWT, the Most Gracious and Most Merciful for ensuring myself to be healthy to carry out my study and to complete this article. I wish to express my sincere gratitude to my supervisor, Dr Ardzulyna Binti Anal, for her enthusiasm, patience, insightful comments, helpful information, practical advice and unceasing ideas that have helped me tremendously. This article would not have been possible without her exceptional support. My sincere appreciation also goes to my family who has been so tolerant and supportive either morally or financially. Thanks for the continuous encouragement, love and emotional supports that they had given all this time. 
DEVELOPMENT

Vol. 10, No. 4, 2021, E-ISSN: 2226-6348 @ 2021 HRMARS

\section{Corresponding Author}

Siti Aisyah binti Maszarry

Universiti Pendidikan Sultan Idris, Malaysia

Email: swookipp@gmail.com

\section{References}

Ang, C. T., \& Lee, L. W. (2013). Pendidikan Seksualiti dalam kalangan murid bermasalah pembelajaran di sekolah menengah: Cabaran dan halangan. Jurnal Bitara Pendidikan 6(1), 53-62. Penerbit Universiti Perguruan Sultan Idris.

Ballan, M. S., \& Freyer, M. B. (2017). The sexuality of young women with intellectual and developmental disabilities: A neglected focus in the American foster care system. Disability and health journal, 10(3), 371-375. https://doi.org/10.1016/j.dhjo.2017.02.005

Carvalho, A. N. L. D., \& Silva, J. P. D. (2018). Sexuality of people with disabilities: a systematic review. Arquivos Brasileiros de Psicologia, 70(3), 289-304.

Eyres, R., Williamson, R. L., Hunter, W., \& Casey, L. (2016). Providing comprehensive sexuality education to students with intellectual and developmental disabilities: Preparing the trainer. Division on Autism and Developmental Disabilities Online Journal, 3(1), 160171.

Frawley, P., \& Wilson, N. (2016). Young People with Intellectual Disability Talking about Sexuality Education and Information. Sexuality and Disability, 34(4): 469-484. https://doi.org/10.1007/s11195-016-9460-x

Gonzálvez, C., Fernández-Sogorb, A., Sanmartín, R., Vicent, M., Granados, L., \& GarcíaFernández, J. M. (2018). Efficacy of sex education programs for people with intellectual disabilities: a meta-analysis. Sexuality and Disability, 36(4), 331-347. https://doi.org/10.1007/s11195-018-9545-9

Grove, L., Morrison-Beedy, D., Kirby, R., \& Hess, J. (2018). The birds, bees, and special needs: Making evidence based sex education accessible for adolescents with disabilities. Sexuality and Disability, 36(4), 313-329. https://doi.org/10.1007/s11195-018-9547-7

Holland-Hall, C., \& Quint, E. H. (2017). Sexuality and disability in adolescents. Pediatric Clinics, 64(2), 435-449. https://doi.org/10.1016/j.pcl.2016.11.011

Ihwani, S. S., Muhtar, A., Musa, N., Ab Rahim, N. A. Z., \& Rashed, Z. N. (2015). Sex education beyond school: Implications for practice and research. Journal of Advanced Review on Scientific Research, 14(1), 12-16.

Khalaf, Z. F., Low, W. Y., Merghati-Khoei, E., \& Ghorbani, B. (2014). Sexuality education in Malaysia: Perceived issues and barriers by professionals. Asia Pacific Journal of Public Health, 26(4), 358-366.

Michielsen, K., \& Brockschmidt, L. (2021). Barriers to sexuality education for children and young people with disabilities in the WHO European region: a scoping review. Sex Education, 1-19. https://doi.org/10.1080/14681811.2020.1851181

Nelson, B., Pettersson, O. K., \& Emmelin, M. (2020). Experiences of teaching sexual and reproductive health to students with intellectual disabilities. Sex Education, 20(4), 398412. https://doi.org/10.1080/14681811.2019.1707652

Rahman, S. F. A. (2020). Memperkasa Anak-Anak Dengan Pendidikan Seksual: Satu Model Islami. Jurnal Dunia Pengurusan, 2(1), 1-11.

https://myjms.mohe.gov.my/index.php/jdpg/article/view/8643 
Rooks-Ellis, D. L., Jones, B., Sulinski, E., Howorth, S., \& Achey, N. (2020). The effectiveness of a brief sexuality education intervention for parents of children with intellectual and developmental disabilities. American Journal of Sexuality Education, 15(4), 444-464. https://doi.org/10.1080/15546128.2020.1800542

Saunders, M. N., Thornhill, A., \& Lewis, P. (2019). Research methods for business students. Pearson education.

Setianti, Y., Nugraha, A., Hafiar, H., \& Damayanti, T. (2017). Teachers' Problematic In Disseminating Information On Sex Education for Adolescents with Disabilities Through Mass Media. https://doi.org/10.2991/aecon-17.2017.62

Shariza, S. (2017). Pembangunan modul latihan pendidikan seksualiti untuk guru program Pendidikan Khas Integrasi (PPKI) peringkat Sekolah Rendah/Shariza Said (Doctoral dissertation, University of Malaya).

Swango-Wilson, A. (2011). Meaningful sex education programs for individuals with intellectual/developmental disabilities. Sex disability, 29, 113-118. https://doi.org/10.1007/s11195-010-9168-2

Treacy, A. C., Taylor, S. S., \& Abernathy, T. V. (2018). Sexual health education for Individuals with disabilities: A call to action. American Journal of Sexuality Education, 13(1), 65-93. https://doi.org/10.1080/15546128.2017.1399492

Ujang, A. (2016). Pembangunan modul pembelajaran WebQuest pendidikan kesihatan untuk guru pelatih murid bermasalah pembelajaraan (Doctoral dissertation, Jabatan Pengurusan, Perancangan dan Dasar Pendidikan, Fakulti Pendidikan, Universiti Malaya).

Wang, M. M., \& NUR, B. (2019). Research on the status quo and the countermeasures of sex education in special schools in Xinjiang. Chinese Journal of Human Sexuality, 28(9), 149.

Wu, J., \& Zeng, S. (2020). Sexuality education for children and youth with disabilities in Mainland China: Systematic review of thirty years. Children and Youth Services Review, 116, 105197. https://doi.org/10.1016/j.childyouth.2020.105197

Yoisangadji, F. (2016). Tingkat Pengetahuan Orang Tua Tentang Pendidikan Seks Pada Anak Sekolah Di Sd Negeri Ngrukeman. Skripsi. Universitas Muhammadiyah Yogyakarta. 